\title{
Activated sludge can support alternative microbial community stables states
}

\author{
Yulin Wang \\ Jun Ye \\ Feng Ju \\ Lei Liu \\ Joel A. Boyd \\ Yu Deng \\ Donovan H. Parks \\ Xiaotao Jiang \\ Xiaole Yin \\ Ben J. Woodcroft \\ Gene W. Tyson \\ Philip Hugenholtz \\ Martin F. Polz \\ Tong Zhang
}

\section{Video Byte}

Keywords: Microbiome, microbial community, alternative stable states, time-series, activated sludge, disturbance, stability, resilience, microbiota, wastewater treatment, microbes, metagenome, metagenomics, metabolic profile, successional dynamics, taxonomy, Proteobacteria, Actinobacteriota

Posted Date: October 13th, 2021

DOI: https://doi.org/10.21203/rs.3.rs-967540/v1

License: (c) (i) This work is licensed under a Creative Commons Attribution 4.0 International License. Read Full License 


\section{Abstract}

Humans rely on microbial communities in both natural and applied settings. One such applied setting is wastewater treatment plants, which use microbial communities to remove pollutants. However, the stability of the taxonomic diversity in these settings is not well understood. To close this gap, researchers examined how the microbial community in activated sludge changed over time in a full-scale wastewater treatment plant. For the first 3 years of a 9-year series, the microbial community fluctuated around a stable average. Then a bleaching event, marked in red under the timeline, abruptly pushed the community to an alternative stable state, where the originally dominant Actinobacteriota were disproportionally depleted and replaced with Proteobacteria, but these taxonomic changes led to little change in either the metabolic profile of the community or system performance. In a fine-scale analysis of dynamics, the researchers identified cohorts that dominated at different periods. In a fine-scale analysis of dynamics, the researchers identified cohorts that dominated at different periods. These cohorts exhibited successional dynamics on both seasonal and longer timescales due to shifts in temperature and changes in mean residence time, respectively. This study suggests that a given set of similar environmental conditions can support different microbial community stable states, but that those different stable states can perform the same cellular functions. 